\title{
In silico screening of anti-inflammatory constituents with good drug-like properties from twigs of Cinnamomum cassia based on molecular docking and network pharmacology
}

\author{
Qing Zhang ${ }^{1}$, Ruolan $\mathrm{Li}^{1}$, Jia Liu', Wei Peng ${ }^{1}$, Yongxiang Gao ${ }^{2}$, Chunjie Wu', \\ Xufeng $\mathrm{Pu}^{1,3 *}$ \\ ${ }^{1}$ School of Pharmacy, ${ }^{2}$ School of Basic Medicine, Chengdu University of Traditional Chinese Medicine, Chengdu 610075, \\ ${ }^{3}$ Chengdu Institute for Food and Drug Control, Chengdu 611137, PR China \\ *For correspondence: Email: pxf68@263.net; Tel: +86-028-85360259
}

\begin{abstract}
Purpose: To investigate by in silico screening the anti-inflammatory constituents of Cinnamomum cassia twigs.

Methods: Information on the constituents of $C$. cassia twigs was retrieved from the online Traditional Chinese Medicines (TCM) database and literature. Inflammation-related target proteins were identified from DrugBank, Online Mendelian Inheritance in Man (OMIM), Therapeutic Target Database (TTD), Genetic Association Database (GAD), and PharmGKB. The identified compounds were filtered by Lipinski's rules with Discovery Studio software. The "Libdock" module was used to perform molecular docking; LibdockScores and default cutoff values for hydrogen bonds and van der Waals interactions were recorded. LibdockScores between the prototype ligand and target protein were set as the threshold; compounds with higher LibdockScores than threshold were regarded as active compounds. Cytoscape software was used to construct active constituent-target protein interaction networks.

Results: Sixty-nine potential inflammatory constituents with good drug-like properties in C. cassia twigs were screened in silico based on molecular docking and network pharmacology analysis. JAK2, mPEGS-1, COX-2, IL-1 3 , and PPARY were considered the five most important target proteins. Compounds such as methyl dihydromelilotoside, hierochin B, dihydromelilotoside, dehydrodiconiferyl alcohol, balanophonin, phenethyl (E)-3-[4-methoxyphenyl]-2-propenoate, quercetin, and luteolin each interacted with more than six of the selected target proteins.

Conclusion: C. cassia twigs possess active compounds with good drug-like properties that can potentially be developed to treat inflammation with multi-components on multi-targets.
\end{abstract}

Keywords: Twigs, Cinnamomum cassia, inflammation, network pharmacology, molecular docking

This is an Open Access article that uses a fund-ing model which does not charge readers or their institutions for access and distributed under the terms of the Creative Commons Attribution License (http://creativecommons.org/licenses/by/4.0) and the Budapest Open Access Initiative (http://www.budapestopenaccessinitiative.org/read), which permit unrestricted use, distribution, and reproduction in any medium, provided the original work is properly credited.

Tropical Journal of Pharmaceutical Research is indexed by Science Citation Index (SciSearch), Scopus, International Pharmaceutical Abstract, Chemical Abstracts, Embase, Index Copernicus, EBSCO, African Index Medicus, JournalSeek, Journal Citation Reports/Science Edition, Directory of Open Access Journals (DOAJ), African Journal Online, Bioline International, Open-J-Gate and Pharmacy Abstracts

\section{INTRODUCTION}

Twigs of Cinnamomum cassia (also called cassia twig in Pharmacopoeia) belong to the Lauraceae family and are an important ancient herbal medicine used in Chinese folk medicine to treat various diseases, including rheumatoid arthritis (RA), cardiac palpitations, amenorrhea, and 
edema [1,2]. Furthermore, the twigs of $C$. cassia (cassia twig) currently remain one of the most commonly used traditional Chinese medicines (TCM) of the Pharmacopoeia of the People's Republic of China [3].

To date, many traditional uses of the twigs of $C$. cassia have been validated by modern pharmacological studies; increasing evidence has revealed that this herbal medicine possesses many activities, including anti-inflammatory, antibacterial, analgesic, antianaphylaxis, antitumor, and diuretic effects [4-6]. Previous phytochemical studies indicated that twigs of $C$. cassia contain various types of natural components, including sesquiterpenoids, diterpenoids, phenylpropanoids, coumarins, lignans, flavonoids, and phenolic glycosides [2,79].

Several studies have suggested that computeraided drug design (CADD) and in silico assessment may be feasible approaches for identifying candidate drugs in the early stage of high-throughput screening [10,11]. Furthermore, molecular docking is a predominant technology for in silico research that is based on docking small molecules to target proteins $[12,13]$. In the present study, the aim was to screen the antiinflammatory components from the twigs of $C$. cassia based on docking-based virtual screening (DBVS) with the Discovery Studio platform (version 4.5.0, Biovea Inc, Omaha, NE, USA). Importantly, the present investigation may be beneficial for identifying potential active agents with reliable anti-inflammatory effects from the twigs of $C$. cassia.

\section{METHODS}

\section{Compound library establishment}

Compounds from the twigs of $C$. cassia were identified from four major databases: Traditional Chinese Medicine Systems Pharmacology Database and Analysis Platform (TCMSP, http://lsp.nwu.edu.cn/tcmsp.php), Traditional Chinese Medicine Integrated Database (TCMID, http://www.megabionet.org/tcmid/), $\quad$ TCM @Taiwan (http://tcm.cmu.edu.tw/zhtw/index.php), and Chemical Database of Traditional Chinese Medicine (CHEM-TCM, http://www.chemtcm.com/). Due to the limitation of the four databases, additional important monomers in twigs of $C$. cassia that were previously reported were also added to our study. The chemical structures of the collected compounds were searched for in Chemical Book (https://www.chemicalbook.com) and SciFinder (https://sso.cas.org). The 2D structures of these compounds were drawn using ChemDraw software (version 14.0, CambridgeSoft, Cambridge, MA, USA).

\section{Selection of inflammation-related target proteins}

Keywords, such as "inflammation," "inflammatory," "inflammatory reactions," and "inflammatory response" were used to search currently known protein targets that are clearly associated with the pathogenesis of inflammation from five major disease databases (DrugBank, OMIM, TTD, GAD, and PharmGKB). Based on the information of species origin, active matrix, resolution, and whether there are known ligands, the un-modeled human target protein crystal complexes with prototype ligands were searched and downloaded from the PDB bank (https://www.rcsb.org).

\section{Molecular docking with Discovery Studio software}

Molecular docking analysis was performed using Discovery Studio software. After importing target proteins, all crystallographic water molecules of the target proteins were cleared from the coordinate set. Next, the "Prepare Protein" module in Discovery Studio was performed to hydrogenate the target protein, supplement the incomplete amino acid residues, and remove the poly-conformation of the target protein and other pretreatments. The binding regions were defined as atoms that were $5 \AA$ around the centroid of the ligand in the crystal structure.

Compounds from twigs of C. cassia were imported into the Discovery Studio software, and the ligand molecules were added with hydrogen atoms and protonated by a strong base using the "Prepare Ligands" module to generate an effective single 3D conformation. Subsequently, Lipinski's and Veber's rules were used to filter out the compounds with poor drug-like properties using Discovery Studio software with the parameters of molecular weight (MW), hydrogen bond donor (HBD), hydrogen bond receptor (HAD), fat-water distribution coefficient (AlogP), number of rotatable bonds (NRBs), and number of rings (NRs). Polar surface area (PSA) was also calculated. Thus, all selected compounds had good chemotaxis, such as good absorption and permeation.

The "Libdock" module of the Discovery Studio was used to perform molecular docking; the standard default settings were used in all calculations. For each of the 10 independent genetic algorithm runs, a default maximum of 
100 genetic operations were performed using the default operator weights and a population size of 100 chromosomes. LibdockScores and default cutoff values for hydrogen bonds and van der Waals interactions were recorded. The LibdockScore was employed to evaluate the affinity between the target proteins and ligands. The LibdockScore between the prototype ligand and target protein was set as the threshold. Compounds with higher Libdockscores with the target protein than the threshold were considered as active compounds for that protein. In addition, the default cutoff values for hydrogen bonds and van der Waals interactions were used to investigate the binding mode between the target proteins and ligands.

\section{Interaction networks between target proteins and ligands}

To establish the interaction networks between target proteins and active constituents in twigs of C. cassia, the molecular docking results of the target proteins and active components were transferred to Cytoscape software (version 3.2.1). For analysis, "Node" represented active compounds and target proteins and "Edge" represented the interaction relationship between the compounds and target proteins. Network parameters contained network degree, node betweenness, and node closeness and were calculated to analyze the interaction network. Larger network parameters indicated a more important node in the network.

\section{RESULTS}

\section{Active constituents with good drug-like properties in twigs of $\boldsymbol{C}$. cassia}

Through database searches and literature reviews, a total of 144 compounds were identified. However, after screening and filtration using Lipinski's rules, 96 potential active compounds were reserved. Furthermore, five parameters (MW, AlogP, NRB, HBA, and HBD) were used to characterize the potential drug-like properties of the candidate active compounds (Table 1). The predicted molecular descriptors revealed that the average MWs of the potential active constituents were lower than 500 (median value is 186.12), average AlogP values were lower than 5.0 (median value is 2.50 ), average NRBs were lower than 5.0 (median value was 2.32), and average HADs and HBDs were lower than 5.0 (median values were 1.80 and 0.64 ).

\section{Molecular docking results}

A total of 186 compound-target protein pairs were acquired via molecular docking using the "Libdock" module on the Discovery Studio platform. Combined analysis indicated that these pairs contained 68 different compounds from twigs of $C$. cassia (Table 2), including 22 sesquiterpenoids, 21 phenylpropanoids, 9 monoterpenoids, 3 flavonoids, and 13 other types of compounds (Table 3). These constituents had higher LibdockScores than the prototype ligand of target proteins, indicating these constituents may be the anti-inflammatory components in twigs of C. cassia. Furthermore, the binding mode between target proteins and active compounds were analyzed via study of the related default cutoff values for hydrogen bonds and van der Waals interactions. The results for proposed binding mode of some of the crucial target proteins and active compounds are shown in Figure 1.

\section{Interaction network analytical data}

As shown in Figure 2, the network contains 79 nodes and 186 edges. The nodes consist of 68 active compounds and 11 inflammatory target proteins. In the network, the red rhombuses represent protein targets and red circles represent active compounds. Furthermore, the node size represents the importance of the target proteins and compounds in the network. In particular, JAK2, mPEGS-1, COX-2, IL-1 $\beta$, and PPARy were considered to be the five most important target proteins of compounds from twigs of $C$. cassia against inflammation. In addition, the node degree, node betweenness, and node closeness in the network were analyzed. Forty-five compounds were identified that act on more than one target protein; the other 23 compounds of twigs of C. cassia only act on a single target protein.

Table 1: Malor molecular descriptors for the potential active components in twigs of $C$. cassia

\begin{tabular}{lcccc}
\hline Molecular descriptor & $\begin{array}{c}\text { Mean } \\
\text { value }\end{array}$ & $\begin{array}{c}\text { Minimum } \\
\text { value }\end{array}$ & $\begin{array}{c}\text { Maximum } \\
\text { value }\end{array}$ & Median value \\
\hline Molecular weight (MWs) & 186.12 & 104.15 & 373.14 & 162.19 \\
Fat-water distribution coefficient (AlogP) & 2.50 & -0.50 & 4.91 & 2.49 \\
Number of rotatable bounds (NRBs) & 2.32 & 0.00 & 7.00 & 2.00 \\
Hydrogen bond acceptor (HADs) & 1.80 & 0.00 & 8.00 & 1.00 \\
Hydrogen bond donor (HBDs) & 0.64 & 0.00 & 4.00 & 0.00 \\
\hline
\end{tabular}




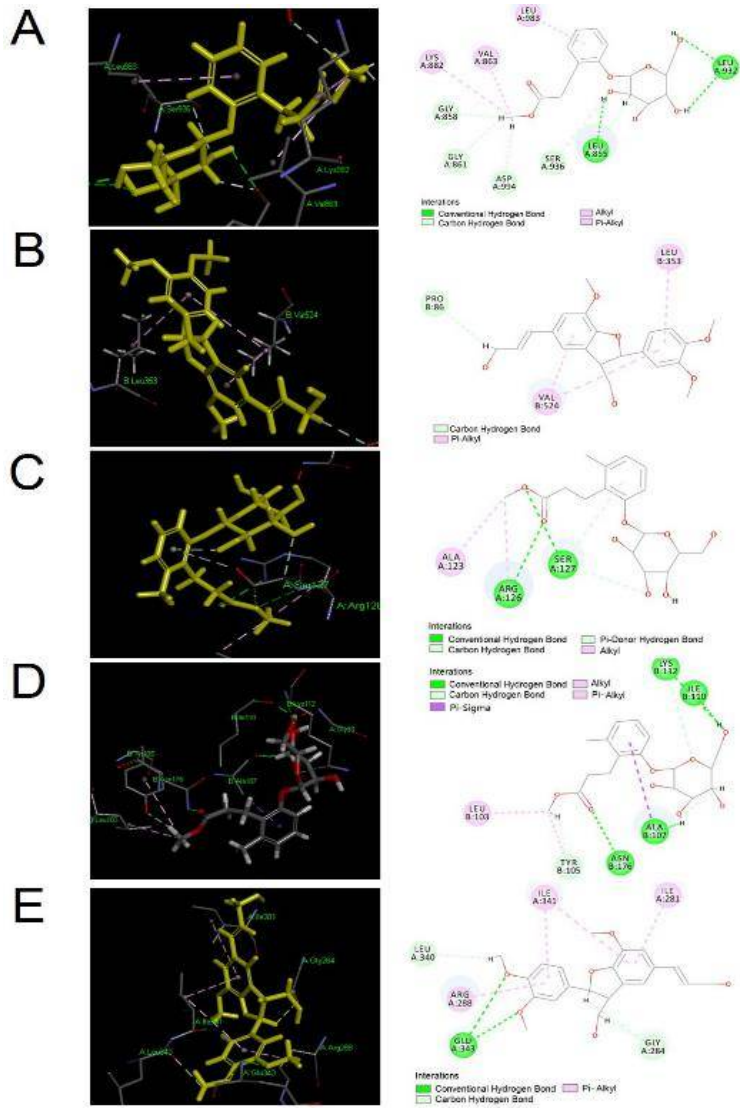

Figure 1: The represented results for proposed docking mode of molecular docking. The action modes of active compounds with specific proteins were analyzed by Discovery studio software. (A) Docking mode of Dihydromelilotoside with JAK-2 (PDB ID: 3E62); (B) Docking mode of Hierochin B with COX-2 (PDB ID: 5IKQ); (C) Docking mode of Methyl dihydromelilotoside with Mpges-1 (PDB ID: 4YL3); (D) Docking mode of Methyl dihydromelilotoside with IL-1 (PDB ID: 4DEP); (E) Docking mode of Hierochin B with PPAR-y (PDB ID: 6E5A)

Table 3: Active compounds of $C$. cassia twigs

\begin{tabular}{llc}
\hline S/no. & Type & Number \\
\hline 1 & Sesquiterpenoids & 22 \\
2 & Phenylpropanoids & 21 \\
3 & Monoterpenoids & 9 \\
4 & Flavonoids & 3 \\
5 & Others & 13 \\
& Total & 68 \\
\hline
\end{tabular}

As seen in Figure 2, C17 (methyl dihydromelilotoside) had the maximum target protein interactions (degree: 11), followed by C26 (Hierochin B, degree: 10), C32 (Dihydromelilotoside, degree: 9), C33 (Dehydrodiconiferyl alcohol, degree: 9), C46 (balanophonin, degree: 8), C13 (Phenethyl (E)-3[4-methoxyphenyl]-2-propenoate, degree: 7), C8 (quercetin, degree: 6), C19 (Luteolin, degree: 6), C68 [(3R,4R)-3,4-di(3-methoxy-4-hydroxyphenyl) dihydrofuran-2-one (3R,4R)-3,4-Di (3-methoxy-4- hydroxyphenyl) dihydrofuran-2-one, degree: 6], and C65 [(E,E)-Farnesol, degree: 6]. Similarly, all selected target proteins interacted with multiple constituents. The target proteins JAK2, COX-2, mPEGS-1, IL-1 $\beta$, and PPAR $y$ were potential targets of $41,37,30,20$, and 16 compounds from twigs of $C$. cassia, respectively (Table 4). These results suggest that the inflammationrelated target proteins can be regulated by multiple components in twigs of $C$. cassia. Additionally, one active constituent could also regulate multiple target proteins related to inflammatory responses, which is consistent with the nature of herbal medicines that treat diseases via multi-components and multi-target synergistic therapy.

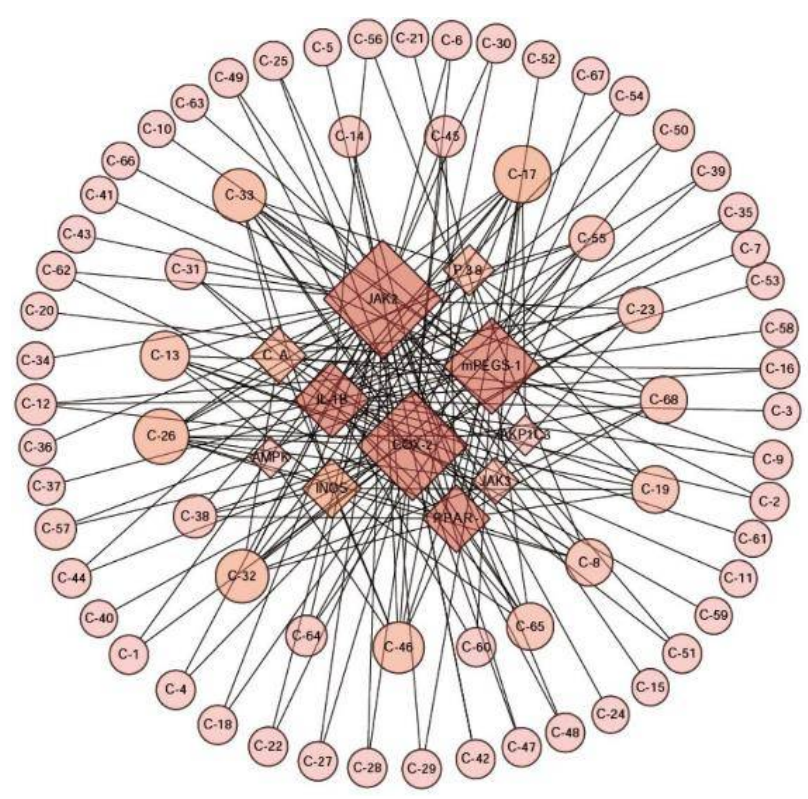

Figure 3: Interaction networks for twigs of $C$. cassia constructed using Cytoscape software (version 3.2.1). The red rhombuses represent protein targets, and red circles represent active compounds

\section{DISCUSSION}

Inflammatory responses can be activated by several factors, including physical injury, microbial infection, immune responses, and chemical damage $[14,15]$. Furthermore, inflammatory reactions occur in various diseases and over-activated inflammatory responses can also result in harmful effects [15]. Thus, controlling inflammation is necessary for protecting the human body. For treating inflammation, the currently available drugs are mainly synthetic drugs, such as corticosteroids and non-steroidal anti-inflammatory drugs (NSAIDs) $[16,17]$.

Trop J Pharm Res, October 2019; 18(10):2128 
Table 2: The potential active constituents in twigs of $C$. cassia

\begin{tabular}{|c|c|c|c|}
\hline ID & Compound & ID & Compound \\
\hline $\mathrm{C} 1$ & trans-Caryophyllene & C35 & Coumarin \\
\hline $\mathrm{C} 2$ & trans-2-Octen-1-ol & $\mathrm{C} 36$ & Coniferaldehyde \\
\hline C3 & Styrene & $\mathrm{C} 37$ & Citral \\
\hline $\mathrm{C} 4$ & Spathulenol & $\mathrm{C} 38$ & Cinnamyl cinnamate \\
\hline C5 & Sativene & C39 & Cinnamic alcohol \\
\hline C6 & Sandasweet & $\mathrm{C} 40$ & Cinnamic acid \\
\hline $\mathrm{C7}$ & Salicylaldehyde & C41 & Cinnamaldehyde \\
\hline $\mathrm{C} 8$ & Quercetin & $\mathrm{C} 42$ & Cedrene \\
\hline $\mathrm{C9}$ & Protocatechuic acid & $\mathrm{C} 43$ & Caffeic acid \\
\hline $\mathrm{C} 10$ & $p$-menthene -2-ene & C44 & $\mathrm{y}$-Cadinene \\
\hline C11 & Phenylethyl alcohol & C45 & Benzyl benzoate \\
\hline C12 & Phenethyl formate & $\mathrm{C} 46$ & Balanophonin \\
\hline $\mathrm{C} 13$ & Phenethyl (E)-3-[4-methoxyphenyl]-2-propenoate & C47 & Aromadendrene \\
\hline $\mathrm{C} 14$ & Nerolidol & $\mathrm{C} 48$ & Acoradiene \\
\hline C15 & Neoclovene & C49 & 8-Epicedrol \\
\hline C16 & Myrcene & $\mathrm{C} 50$ & 4-Hydroxybenzoic acid \\
\hline $\mathrm{C} 17$ & Methyl dihydromelilotoside & C51 & 4-Ethenyl-a,a,4-cyclohexanemethanol \\
\hline C18 & Methyl cinnamate & C52 & 4-Carvomenthol \\
\hline C19 & Luteolin & $\mathrm{C} 53$ & 4-Acetyl-1-methyl-1-cyclohexene \\
\hline $\mathrm{C} 20$ & Linalool & C54 & 3-Phenylpropanal \\
\hline $\mathrm{C} 21$ & Limonene & C55 & $\begin{array}{l}\text { 3-Isoxazolecarboxylicacid, 4-(hydroxymethyl)-5-(3- } \\
\text { iodophenyl)-, ethyl ester }\end{array}$ \\
\hline $\mathrm{C} 22$ & Ledol & C56 & 3,7-Dimethyl-1,3,6-Octatriene \\
\hline $\mathrm{C} 23$ & Kaempferol & C57 & 2-Hydroxyl cinnamaldehyde \\
\hline $\mathrm{C} 24$ & Isosativene & C58 & 1-Phenyl-1,2-propanedione \\
\hline $\mathrm{C} 25$ & Isocaryophyllene & C59 & 1-Methylethylbenzene \\
\hline $\mathrm{C} 26$ & Hierochin B & $\mathrm{C} 60$ & 1-Ethoxy-2-propanol \\
\hline $\mathrm{C} 27$ & Guaiol & C61 & 1-ethenyl-4-methoxybenzene \\
\hline $\mathrm{C} 28$ & Globulol & $\mathrm{C} 62$ & 1,6-Dimethyl-4-(1-methylethyl)naphthalene \\
\hline $\mathrm{C} 29$ & Eugenol & $\mathrm{C} 63$ & 1,1'-[ethylidenebis(oxy)]bis-propane \\
\hline $\mathrm{C} 30$ & Eremophilene & $\mathrm{C} 64$ & (Z)-Cinnamyl acetate \\
\hline C31 & $\begin{array}{l}\text { Dimethyl-6-(4-methyl-3-pentenyl)-dicyclo [3.1. 1] } \\
\text { heptyl-2-ene }\end{array}$ & C65 & $(E, E)-$ Farnesol \\
\hline $\mathrm{C} 32$ & Dihydromelilotoside & C66 & (E)-3-(2-methoxyphenyl)acrylic acid \\
\hline C33 & Dehydrodiconiferyl alcohol & $\mathrm{C} 67$ & $\begin{array}{l}\text { (E)-2-methoxyethenyl-benzene } \\
\text { (3R,4R)-3,4-di(3-methoxy-4-hydroxyphenyl) }\end{array}$ \\
\hline C34 & Cyclosativene & C68 & $\begin{array}{l}\text { dihydrofuran-2-one }(3 R, 4 R) \\
-3,4-d i(3-m e t h o x y-4-h y d r o x y p h e n y l) \text { dihydrofuran-2- } \\
\text { one }\end{array}$ \\
\hline
\end{tabular}

Table 4: The 11 target proteins investigated in the present study

\begin{tabular}{|c|c|c|c|c|c|}
\hline PDB ID & Target protein & Abbreviations & Gene & Degree & Betweenness \\
\hline 6C9J & $\begin{array}{l}\text { AMP-activated protein } \\
\text { kinase }\end{array}$ & AMPK & PTEN & 3 & 0.0003 \\
\hline $5 \mathrm{IKQ}$ & Cyclooxygenase-2 & cox-2 & PTGS2 & 37 & 0.2520 \\
\hline 3E7G & INOS & iNOS & NOS2 & 12 & 0.0151 \\
\hline 3E62 & Janus kinase (JAK)-2 & JAK2 & JAK-2 & 41 & 0.3710 \\
\hline 4YTC & Janus kinase (JAK) 3 & JAK3 & JAK-3 & 6 & 0.0026 \\
\hline 4DEP & IL-1 $\beta$ & IL-1 $1 \beta$ & IL-1 $1 \beta$ & 20 & 0.1802 \\
\hline 5GMM & Carbonic anhydrase I & CA I & CA1 & 10 & 0.0091 \\
\hline 50MG & p38a & P38 a & MAPK14 & 8 & 0.0053 \\
\hline $6 \mathrm{E} 5 \mathrm{~A}$ & PPAR y & PPAR-Y & PPARG & 16 & 0.0318 \\
\hline & $\begin{array}{l}\text { mPGES-1 } \\
\text { Phosphatidylinositol } 4,5- \\
\text { bisphosphate 3-kinase } \\
\text { catalytic subunit alpha }\end{array}$ & Mpges-1 & & 30 & 0.3766 \\
\hline 4YL3 & $\begin{array}{l}\text { isoform } \\
\text { Phosphatidylinositol 4,5- } \\
\text { bisphosphate 3-kinase } \\
\text { catalytic subunit alpha } \\
\text { isoform }\end{array}$ & & PTGES & & \\
\hline 3UGR & AKR1C3 & AKR1C3 & AKR1C3 & 3 & 0.0002 \\
\hline
\end{tabular}


However, these synthetic drugs can have some bothersome side-effects, including gastrointestinal disorders, hepatorenal toxicity, and some cardiovascular toxity [18,19]. Therefore, finding a novel candidate antiinflammatory drug with low toxicity is crucial. Importantly, several scientific investigations have suggested that natural agents from herbs or plants possess a wide range of pharmacological activities, such as anti-inflammatory, antitumor, antibacterial, and antioxidant effects [15,20]. Thus, natural agents are consequently valuable resources for drug discovery.

For TCMs and other herbal medicines, oral administration is the predominant method for treating diseases. Thus, potential active constituents from herbal medicines must have favorable bio-activities that include good absorptive properties and an oral bioavailability profile requiring good solubility, permeability, and lipophilicity $[21,22]$. Lipinski's rule is a commonly used standard for evaluating drug-like properties [23]. This standard includes: (I) MW lower than $500 \mathrm{Da}$; (II) number of hydrogen bond donors less than 5; (III) number of hydrogen bond receptors less than 10; (IV) fat-water distribution coefficient less than 5; and (V) number of rotatable keys less than 10 . Monomers following Lipinski's rules may possess better drug-like properties for oral drugs than larger complexes $[12,24]$. Here, before molecular docking, all 144 candidate compounds in twigs of $C$. cassia were filtered by Lipinski's rules, and 97 compounds fit the criteria for the molecular docking study.

Molecular docking is a predominant strategy for high-throughput drug screening based on in silico CADD, and has proven to be a useful technique for identifying active constituents from extensive candidate chemical compounds via calculating the affinity and predicting the binding model of target proteins and ligands [13,21]. During molecular docking, the docking score is the sum of van der Waals interactions, coulombic interactions, and formation of hydrogen bonds, and is the dominant index for evaluating the affinity between target proteins and candidate compounds. In the present study, 69 constituents in twigs of $C$. cassia showed potential binding abilities to the selected target proteins.

Network pharmacology is a feasible approach for studying bioactive constituents and molecular mechanisms of herbal medicines [25,26]. Furthermore, this technique could be applied to interpret the molecular mechanisms of herbal medicines from a holistic viewpoint [27]. Cytoscape is a useful tool for visual analysis of the interaction networks between target proteins and their ligands [28]. We established an interaction network revealing that the potential active components in twigs of $C$. cassia were closely related to the target proteins of JAK2, COX-2, mPEGS-1, IL-1 $\beta$, and PPAR $\gamma$ with node degrees of $41,37,30,20$, and 16 , respectively. Additionally, the results indicated that the active constituents from twigs of $C$. cassia potentially regulate multiple target proteins related to inflammatory responses, and that over 40 compounds in twigs of $C$. cassia act on more than one target protein. In particular, methyl dihydromelilotoside, hierochin B, dihydromelilotoside, dehydrodiconiferyl alcohol, balanophonin, phenethyl (E)-3-[4-methoxyphenyl]-2-propenoate, quercetin, and luteolin, affect at least six target proteins related to inflammatory responses. It is generally recognized that TCMs and herbal medicines effectively treat various diseases via "multi-components," "multi-targets," and "multi-approaches" [29,30]; these characteristics are highly consistent with our findings via interaction network analysis.

\section{CONCLUSION}

Molecular docking and network pharmacology were successfully employed to screen the antiinflammatory constituents of $C$. cassia twigs, with a total of 69 potential active compounds found to possess potential drug-like properties. These findings will facilitate the development of useful agents from $C$. cassia twigs for the management of inflammatory disorders.

\section{DECLARATIONS}

\section{Acknowledgement}

This work was supported by the supported by Sichuan Science and Technology Program (no. 2019JDRC0074), National Science and Technology Major Project of the Ministry of Science and Technology of China (no. 2018ZX09721004-009-002), and China Postdoctoral Science Foundation (no. 2018M631071).

\section{Conflict of interest}

No conflict of interest is associated with this work.

\section{Contribution of authors}

We declare that this work was done by the authors named in this article and all liabilities 
pertaining to claims relating to the content of this article will be borne by the authors.

\section{Open Access}

This is an Open Access article that uses a funding model which does not charge readers or their institutions for access and distributed under the terms of the Creative Commons Attribution License (http://creativecommons.org/licenses/by/ 4.0) and the Budapest Open Access Initiative (http://www.budapestopenaccessinitiative.org/rea d), which permit unrestricted use, distribution, and reproduction in any medium, provided the original work is properly credited.

\section{REFERENCES}

1. Sun L, Liu LN, Li JC, Lv YZ, Zong SB, Zhou J, Wang ZZ, Kou JP, Xiao W. The essential oil from the twigs of Cinnamomum cassia Presl inhibits oxytocin-induced uterine contraction in vitro and in vivo. $J$ Ethnopharmacol 2017; 206: 107-114.

2. Liu X, Yang J, Fu J, Xie TG, Jiang PC, Jiang ZH, Zhu $G Y$. Phytochemical and chemotaxonomic studies on the twigs of Cinnamomum cassia (Lauraceae). Biochem Syst Ecol 2018; 81: 45-48.

3. Editorial Committee of Chinese Pharmacopoeia. 2015. Chinese Pharmacopoeia, vol 1. (2015ed.). China Medical Science and Technology Press: Beijing; pp. 276.

4. Shin WY, Shim DW, Kim MK, Sun X, Koppula S, Yu SH, Kim HB, Kim TJ, Kang TB, Lee KH. Protective effects of Cinnamomum cassia (Lamaceae) against gout and septic responses via attenuation of inflammasome activation in experimental models. J Ethnopharmacol 2017; 205:173-177.

5. Yu CH, Chu SC, Yang SF, Hsieh YS, Lee CY, Chen PN. Induction of apoptotic but not autophagic cell death by Cinnamomum cassia extracts on human oral cancer cells. J Cell Physiol 2019; 234(4):5289-5303.

6. Liang MT, Yang CH, Li ST, Yang CS, Chang HW, Liu CS, Cham TM, Chuang LY. Antibacterial and antioxidant properties of Ramulus Cinnamomi using supercritical CO2 extraction. Eur Food Res Technol 2008; 227:13871396.

7. Guoruoluo Y, Zhou H, Zhou J, Zhao H, Aisa HA, Yao G. Isolation and characterization of sesquiterpenoids from Cassia buds and their antimicrobial activities. J Agric Food Chem 2017; 65(28): 5614-5619.

8. Zhou L, Tuo $Y$, Hao $Y$, Guo $X$, Tang $W$, Xue $Y$, Zeng J, Zhou Y, Xiang M, Zuo J, Yao G, Zhang Y. Cinnamomols $A$ and $B$, immunostimulative diterpenoids with a new carbon skeleton from the leaves of Cinnamomum cassia. Org Lett 2017; 19(11): 3029-3032.
9. Xu F, Wang DJ, Zeng N. Review on chemical components of rimulus cinnamon essential oil. Nat Prod Res Dev 2017; 29: 532-541.

10. Peng $W$, Shen $H$, Lin B, Han P, Li C, Zhang Q, Ye B, Rahman K, Xin H, Qin L, Han T. Docking study and antiosteoporosis effects of a dibenzylbutane lignan isolated from Litsea cubeba targeting Cathepsin $K$ and MEK1. Med Chem Res 2018; 27: 2062-2070.

11. Zheng $Y, L v L$. The application of the Computer Aided Drug Design in drugs synthesis. Qilu Pharm Affair 2008; 27: 614-616.

12. Zhang $H, Y e X, H u C$, Yang $Y$, Xie D. Virtual screening of anti-inflammatory active Components from Smilax china L. J Hubei Univ Chin Med 2018; 20: 44-47.

13. Braga RC, Alves VM, Silva AC, Nascimento $M N$, Silva $F C$, Liao $L M$, Andrade $C H$. Virtual screening strategies in medicinal chemistry: the state of the art and current challenges. Curr Top Med Chem 2014;14(16):1899-912.

14. Gregory M, Barton A. Calculated response: control of inflammation by the innate immune system. $J$ Clin Invest 2008; 118: 413-420.

15. Wang $Q H$, Kuang $H X$, Su $Y$, Sun $Y P$, Feng J, Guo $R$, Chan K. Naturally derived anti-inflammatory compounds from Chinese medicinal plants. J Ethnopharmacol 2013; 146: 9-39.

16. Thakur S, Riyaz B, Patil A, Kaur A, Kapoor B, Mishra V. Novel drug delivery systems for NSAIDs in management of rheumatoid arthritis: An overview. Biomed Pharmacother 2018; 106: 1011-1023.

17. Andersson AK, Li C, Brennan FM. Recent developments in the immunobiology of rheumatoid arthritis. Arthritis Res Ther 2008; 10: 204.

18. Kokate $A, L i X$, Williams $P J$, Singh $P$, Jasti BR. In silico prediction of drug permeability across buccal mucosa. Pharm Res 2009; 26:1130-1139.

19. Lipinski CA, Lombardo F, Dominy BW and Feeney PJ: Experimental and computational approaches to estimate solubility and permeability in drug discovery and development settings. Adv Drug Deliv Rev 2001; 46: 326.

20. Yuan H, Ma Q, Cui H, Liu G, Zhao X, Li W and Piao G. How Can Synergism of Traditional Medicines Benefit from Network Pharmacology? Molecules 2017; 22: 1135.

21. Hopkins AL. Network pharmacology: the next paradigm in drug discovery. Nat Chem Biol 2008; 4: 682-690.

22. Huang J, Cheung F, Tan HY, Hong M, Wang N, Yang J, Feng $Y$, Zheng $Q$. Identification of the active compounds and significant pathways of yinchenhao decoction based on network pharmacology. Mol Med Rep 2017; 16:458345927.

23. Cui Y, Li C, Zeng C, Li J, Zhu Z, Chen W, Huang A, Qi X. Tongmai Yangxin pills anti-oxidative stress alleviates cisplatin-induced cardiotoxicity: Network pharmacology analysis and experimental evidence. Biomed Pharmacother. 2018; 108:1081-1089. 